\title{
Desenvolvimento do jogo Nós para ensino e aprendizagem de Português Língua de Acolhimento
}

Development of the Nós card game for teaching and learning Portuguese as a Host Language

MAEDA, Jamile; Graduanda em Design, Bacharel e Licenciada em Letras; Universidade de Brasília jamilemaeda@gmail.com

TORRES, Camila; Mestre em Design; Universidade de Brasília

camila.lombardi@gmail.com

TEIXEIRA, Julia; Graduanda em Design; Universidade de Brasília

julialozzi@gmail.com

\section{Resumo}

Este artigo relata a criação do Nós, um jogo de cartas instrucional que busca auxiliar professores no ensino de português língua de acolhimento para refugiados e imigrantes em situação de vulnerabilidade. $\mathrm{O}$ jogo é semicooperativo e tem como principal objetivo que seus jogadores formulem orações e períodos semântica e sintaticamente completos de acordo com o português do Brasil, como falado por um nativo. O processo em design descreve etapas de exploração, definição, ideação, prototipagem e aplicação. Como conclusão parcial, compreende o designer como agente de mudança social e aponta para necessidades de novos testes a serem realizados em campo e adequações gráficas. Este projeto foi desenvolvido em parceria com o Núcleo de Ensino e Pesquisa em Português para Estrangeiros-NEPPE.

Palavras Chave: jogo instrucional; português; língua de acolhimento; processo em design.

\begin{abstract}
In this article, we revolve around the conception of Nós, an educational card game that seeks to assist the teaching of Portuguese as a Host Language to refugees and immigrants in vulnerable situations. The card game is semi-cooperative and its main objective is building, along with other players, sentences with full meaning according to the Brazilian Portuguese language, as spoken by a native. The design process consists of exploring, defining, developing, prototyping and testing. Our first conclusions show the importance of the designer as a socially engaged agent, capable of making changes, and they point to the necessity of more tests of real use and graphic adjustments. This project was developed in collaboration with Núcleo de Ensino e Pesquisa em Português para Estrangeiros-NEPPE.
\end{abstract}

Keywords: educational game, Portuguese, Host Language, design process. 


\title{
1 Introdução
}

O jogo Nós é um material paradidático complementar ao ensino de português do Brasil, concebido em parceria com Núcleo de Ensino e Pesquisa em Português para Estrangeiros (NEPPE). Este é uma iniciativa do Departamento de Línguas Estrangeiras e Tradução da Universidade de Brasília (UnB) e era coordenado, na época, por Lúcia Maria de Assunção Barbosa.

O núcleo de ensino possui um projeto voltado para atender refugiados e imigrantes em situação de vulnerabilidade denominado ProAcolher, um curso gratuito de português língua de acolhimento oferecido uma vez por semestre letivo em três níveis de ensino: iniciante, intermediário e intermediário-avançado, com duração total de 60 horas cada.

A condição de refúgio é uma proteção prevista em lei (no 9.474/1997) que o governo brasileiro concede a estrangeiros que sofrem perseguições por motivos de raça, religião, nacionalidade, grupo social ou posicionamento político, ou que estejam em situação de risco, sofrendo, em seu país de origem, uma grave e generalizada violação de direitos humanos. Imigrantes em vulnerabilidade saem de seus países por motivos outros que não os qualificados como refúgio, mas que ainda assim os compelem a deixar suas pátrias; são exemplos os desastres naturais, como o sismo no Haiti em 2010.

\section{O verbete língua de acolhimento foi cunhado com base no verbo acolher,}

\begin{abstract}
que direciona, de imediato, aos verbos alojar, asilar, acomodar e recolher, por exemplo. Desse modo, as plurissignificações a que esse verbo remete são auxiliares na proposição de um ensino e de uma aprendizagem de língua de acolhimento em um plano mais afetivo, com fortes aproximações com outra base sinonímica, na qual o sentido de alteridade está posto. Referimo-nos especialmente às ações de aceitar, atender e ouvir, nas quais é possível antever que a língua que acolhe é a mesma que abriga e protege. Nesse sentido, a valorização e o fortalecimento das línguas faladas pelo público que está sendo acolhido são imprescindíveis e tal reconhecimento sustenta-se e ganha corpo considerando-se os benefícios do plurilinguismo para a aprendizagem de uma nova língua. (BARBOSA \& SÃO BERNARDO apud CAVALCANTI, 2017, p. 434-437)
\end{abstract}

Ele surgiu no programa Portugal Acolhe, que desenvolveu, em 2001, cursos de português exclusivos para imigrantes e refugiados adultos. Este conceito não deve ser confundido com a noção de língua estrangeira ou de segunda língua. Para o público, geralmente adulto, recémchegado em uma realidade linguístico-cultural não vivenciada anteriormente, o uso da língua está ligado a um saber fazer, a novas tarefas de comunicação que devem ser realizadas na língua-alvo. Não se relaciona apenas ao âmbito profissional, mas também a tarefas que divergem da cultura de origem (GROSSO, 2010).

A proposta de concepção de um jogo para o público citado se deu por meio de um briefing definido pela coordenadora e por professoras do NEPPE na primeira aproximação com o núcleo. Para o grupo de designers, a palavra jogo foi compreendida como projeto potencializador da transformação social, em que o espaço de simulação se faz espaço para a aprendizagem de novos comportamentos (BARROS, 2016). Logo, objetivou-se o desenvolvimento de um meio capaz de proporcionar o deslocamento dos indivíduos participantes (jogadores) de seus contextos de vulnerabilidade linguística para um ambiente em que o risco de se cometer erros cotidianos de comunicação é minimizado e acolhido como processo de aprendizagem.

Ao se tratar o design como área de conhecimento capaz de integrar outras disciplinas para se conceber soluções de informação (KNEMEYER, 2003), buscou-se a compreensão dos processos 
estabelecidos no ensino-aprendizagem oferecido pelos professores do núcleo de ensino, da sintaxe da língua portuguesa e do perfil dos aprendizes. Em concordância com Knemeyer (2003) e Shedroff (1999), tal etapa foi fundamental para os procedimentos de design de informação e de interação subsequentes, por levantar dados acerca da construção de conhecimento e de como este potencialmente aprimora operações dos indivíduos.

Como parte do método exploratório, foi realizada uma pesquisa em campo durante aulas regulares e atividades de confraternização do núcleo e foram feitos registros, em cadernetas e por fotografias, e entrevistas presenciais, via e-mail e aplicativo WhatsApp com alunos, professoras e com a coordenadora. As informações levantadas conduziram à definição do problema e aos requisitos de projeto, dando origem a insumos para a fase de ideação de objetivos, estrutura e mecânica do jogo - tema central do presente relato. Como resultado tangível, foi executado e apresentado à equipe do NEPPE um protótipo do jogo Nós. Este processo em design foi fundamentado no Design Thinking difundido por Brown (2010) e, por consequência, no modelo Double Diamond concebido pelo British Council (2015).

\section{Pesquisa em Campo e Requisitos do Projeto}

A participação em aulas do projeto ProAcolher e a convivência em outros momentos de integração dos aprendizes, durante os meses de outubro e novembro de 2016, foi essencial para se conhecer o contexto em que estavam inseridos os alunos, como o núcleo se organizava e como era a relação professor-aluno (Figura 1). Como resultado da observação participante (HAGUETTE, 2010) e de entrevistas formais e informais realizadas, novos dados surgiram a respeito do contexto de aprendizagem e dos futuros usuários do jogo.

Figura 1 - Registro feito em campo durante uma das aulas do nível intermediário. Na foto, Henri Makika apresenta seu país de origem, o Congo

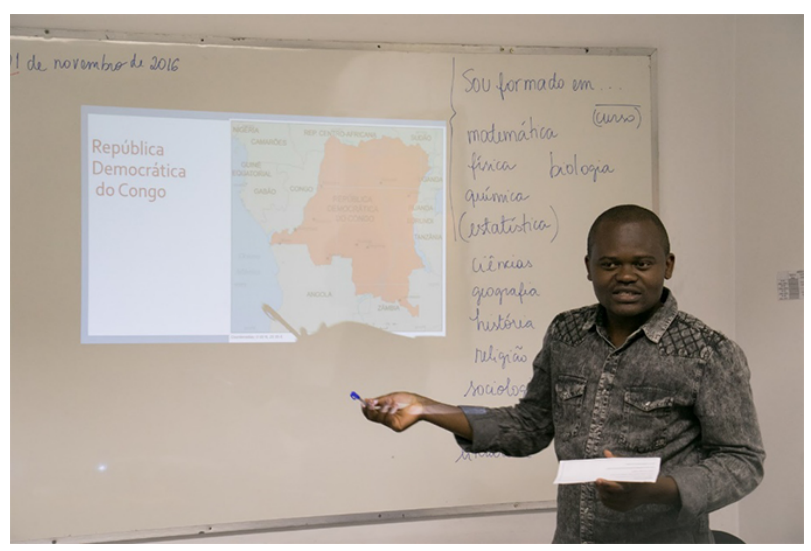

Fonte: Jamile Maeda (2016)

Sobre a dinâmica do ProAcolher, soube-se que não há avaliações que qualifiquem a conclusão de um nível, o aprendiz é convidado a seguir à próxima etapa ao terminar a anterior. É de sua escolha repetir o curso ou seguir adiante. Ainda, os refugiados e imigrantes em situação de vulnerabilidade podem se inscrever a qualquer momento do curso. Isso significa que todas as turmas do projeto são de uma complexa heterogeneidade: há indivíduos com diferentes níveis de conhecimento da língua portuguesa e de tempo de chegada no Brasil; suas origens, culturas e idades são igualmente diversas. Qualquer que tenha sido o motivo de imigração ao Brasil, essas 
pessoas precisam de autonomia linguística em um contexto social, econômico, político que não Ihe é familiar.

Ensinar português língua de acolhimento, então, requer uma didática muito diferente daquela usada para o ensino de português como língua materna ou como segunda língua. Seu principal objetivo é que os refugiados e imigrantes em situação de vulnerabilidade possam ser, de fato, inseridos na sociedade, no mercado de trabalho e em oportunidades de formação; buscar auxílio em serviços públicos, como hospitais e delegacias; realizar tarefas cotidianas, como ir ao supermercado, adquirir itens de necessidade e desejo; manter uma conversa com colegas, entre outros. As aulas raramente seguem planejamentos estritos e com exposições longas; por vezes, os aprendizes trazem suas necessidades à aula e as professoras elaboram conteúdos temáticos direcionadas a conhecimentos de ordem prática e de inclusão social.

Mediante observações e relatos, foram diagnosticadas dificuldades na expressão oral de períodos com sentido completo. Ainda que os aprendizes conseguissem se apropriar de palavras separadas e orações simples, havia grande dificuldade em formular um período cujo verbo concordasse com o sujeito ou cujo objeto seguisse a regência correta do verbo. Estruturas como 'eu cozinha (sic)' ou 'vem com (sic) ônibus' eram recorrentes durante a observação. Sabe-se que tais problemas não configuram um impedimento ao diálogo informal, entretanto podem dificultar momentos em que é necessário descrever a situação com precisão, como em entrevistas de emprego ou em consulta com médico. Esse tipo de ocorrência suscitou ideias para a concepção sobre o principal objetivo do jogo: construir períodos gramaticais com sentido completo, de acordo com o português do Brasil, como falado por um nativo. Isso significa que oralidades e alguns desvios à gramática normativa que já são aceitos por nativos, como 'me liga' (sic) e 'a gente vai na escola' (sic), são considerados como corretos nesse contexto.

Esse objetivo não contempla somente o exercício da concordância e da regência verbal, quis-se explorar também uma experiência linguística completa, que atendesse aos problemas mais expressivos, como listado por Ançã (2008): concordância das formas verbais, utilização da preposição, estrutura da frase, pronúncia, formação dos tempos verbais e vocabulário. O jogo busca possibilitar a aprendizagem de palavras do português do Brasil usadas no cotidiano do falante nativo e outras com as quais elas se relacionam semanticamente, além de conetivos de orações. Procura-se alcançar ainda o exercício da pronúncia e da fluência oral.

\section{Jogos Cooperativos e Definição da Mecânica do Jogo}

A partir do reconhecimento dos requisitos de projeto e da definição do objetivo, deu-se início à pesquisa de referências em jogos físicos de múltiplos jogadores, sendo investigadas, em especial, possibilidades de estruturas e de mecânicas para formulação de alternativas. Após experimentação de diversos tipos disponíveis no mercado, a possibilidade de configurar a solução do projeto em cartas apresentou-se como a mais adequada. Essa categoria de jogos pode ser compreendida como aquela em que o elemento sorte é formalizado pelas interações de embaralhar e apanhar ou distribuir seus componentes (MIURA; BARROS, 2016). De maneira lúdica, essas ações atuam como motivadores externos que implicam reações dos jogadores ao que antes estava incerto - momento de orientação do comportamento do indivíduo. Cartas sorteadas como elementos motivadores se assemelham, pois, com os fortuitos presentes nas interações verbais cotidianas. Ao se apropriar da estrutura carta como parte da resposta ao briefing, categorias de palavras poderiam ser exploradas em baralhos com características visuais próprias, 
mais elementos poderiam ser acrescidos caso fosse pertinente uma evolução do baralho e as partidas poderiam contemplar ainda permutas, formação de conjuntos e o diálogo entre jogadores.

O contexto propiciado pelo ProAcolher faz da convivência um recurso para o processo de ensino e aprendizagem, do qual participam professores brasileiros e pessoas de diversos países de origem (dentre eles, Afeganistão, Bangladesh, Congo, Cuba, Egito, Gana, Haiti, Irã, Jamaica, Nigéria, Paquistão, Síria, Tongo, Tunísia,Turquia e Venezuela). Para explorar a troca solidária de conhecimentos na mecânica do jogo frente à diversidade, fez-se uma aproximação com o conceito de jogo cooperativo.

O jogo cooperativo é um instrumento facilitador no aprendizado de um conhecimento e na inserção de um indivíduo em um contexto social. Por meio da integração dos jogadores, o indivíduo é motivado a cooperar para o bem da coletividade (BROTTO, 2012). Segundo Soler (2006, p. 23), "[...] os participantes jogam uns com os outros, em vez de um contra os outros. Jogase para superar desafios. São jogos para compartilhar, unir pessoas, despertar a coragem para assumir riscos". Já o jogo de caráter competitivo é excludente e tem seu propósito na vitória individual ou de poucos. No intermédio disso, há uma abordagem semicooperativa (BROTTO, s.d.; MAIA, MAIA, MARQUES, 2007): mesmo que haja um ganhador no final, as mesmas oportunidades são oferecidas a todos e a dinâmica do jogo foca na construção coletiva.

A partir dessa investigação, ponderou-se agregar à dinâmica do Nós oportunidades de acolhimento ao erro e uma conclusão de uma rodada que fosse também um vitória compartilhada por todos os envolvidos. Adotando-se a perspectiva de jogo semicooperativo e após a realização de inúmeras experimentações (Figura 2) na fase de ideação, foram definidos o baralho de cartas e os critérios que demarcam o turno de um jogador, a conclusão de uma rodada e o fim do jogo, como explicado a seguir.

Figura 2 - Realização de experimentos da mecânica do jogo com protótipo de baixa fidelidade

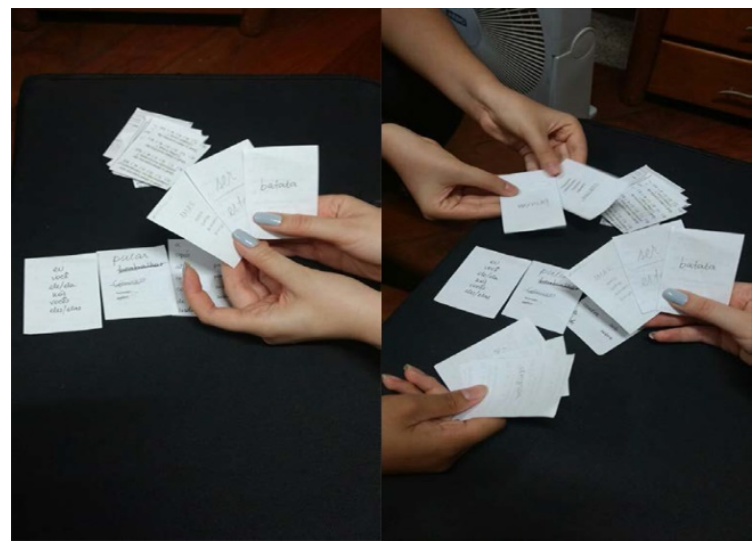

Fonte: Jamile Maeda (2016)

Há no jogo três tipos de carta, denominadas Únicas, Amigas e Coringas. O tipo Única se apresenta com apenas um exemplar cada e traz uma ou duas palavras que dão noção semântica às orações - são elas substantivos, adjetivos, advérbios e verbos. O baralho de Amigas contém cartas com pronomes, preposições e conectivos e auxiliam as cartas Únicas a completar o período. Já a carta Coringa pode substituir qualquer palavra das cartas Únicas. Para começar, embaralham- 
se duas pilhas, uma de cartas Únicas e Coringas e outra de cartas Amigas, que são deixadas sobre a mesa de verso para cima. De ambas as pilhas, os jogadores tiram secreta e aleatoriamente três Únicas e duas Amigas, ficando, em mão, com cinco cartas.

Em uma rodada, cada jogador precisa colocar uma carta na mesa, disposta de modo a favorecer o sentido semântico para se construir uma oração ou um período junto às demais sugere-se que a pessoa que se encontra há menos tempo no Brasil inicie a partida. Cartas como verbos, preposições, pronomes e conectivos possibilitam que aquele que a jogou na mesa escolha sua variação (por exemplo, pessoa do pronome, tempo, número e modo do verbo), a partir de dicas presentes na própria carta, como ilustrado na Figura 3. O jogador deve, em seguida, enunciar a palavra inserida por ele e o conjunto de cartas que já está sobre a mesa. Neste momento, as informações são relacionadas pelo jogador a partir da estruturação coletiva de dados (cartas), de modo que este seja capaz de conduzir um processo de comunicação aos demais. Está relacionado a decisões de design de interação que consideram a experiência do usuário como meio de exposição dos aprendizados (SHEDROFF, 1999).

Figura 3 - Exemplo de cartas que apresentam variação de pronomes, verbo e advérbio, respectivamente

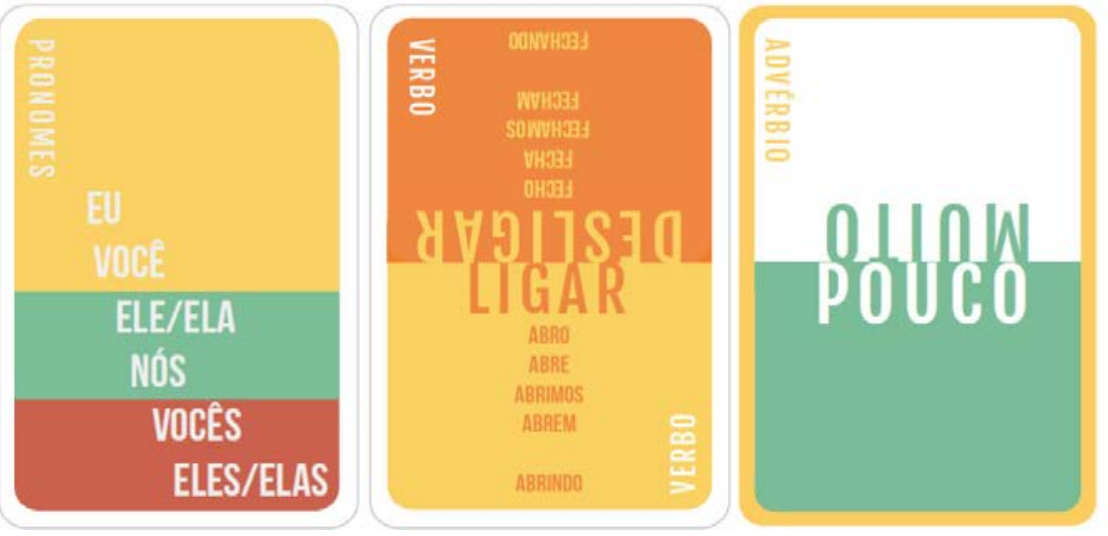

Fonte: Jamile Maeda (2016)

Caso algum jogador não tenha cartas para jogar em seu turno, deve comprar uma carta de cada pilha na mesa. Quem auxilia no processo de formação da oração ou do período com sentido completo é o patrulheiro, nome dado ao mediador do jogo e detentor de grande conhecimento sobre a língua portuguesa, podendo ele ser um aprendiz com mais experiência ou um professor. Nos casos em que um jogador lança uma carta que não se adequa sintática ou semanticamente na construção do período, este mediador pode comentar sobre o ocorrido, apontando caminhos possíveis e orientando, junto aos demais participantes, um novo lance do mesmo jogador.

A rodada termina quando o patrulheiro concordar que o período está formado dentro das estruturas gramaticais corretas, está semanticamente completo e sintaticamente adequado. $\mathrm{O}$ jogador que colocou a última carta ganha um marcador de conclusão, peça física que fica com o jogador até o final da partida. Aquele que reunir três marcadores vence a partida.

Para a confecção de um protótipo (Figura 4), foram adotadas soluções gráficas iniciais que se demonstrariam suficientes para a execução de testes em ambiente controlado e em campo, a serem revisadas e aprofundadas após os primeiros resultados obtidos. A concepção visual das cartas apoiou-se em texto, ilustrações e aplicação de quatro cores além do branco. 
Figura 4 - Jogo Nós, protótipo impresso acompanhado por embalagem, manual e marcadores de conclusão. Na foto, um exemplo de possível período completo formado no jogo: "O brasileiro gosta muito de comer arroz e feijão"

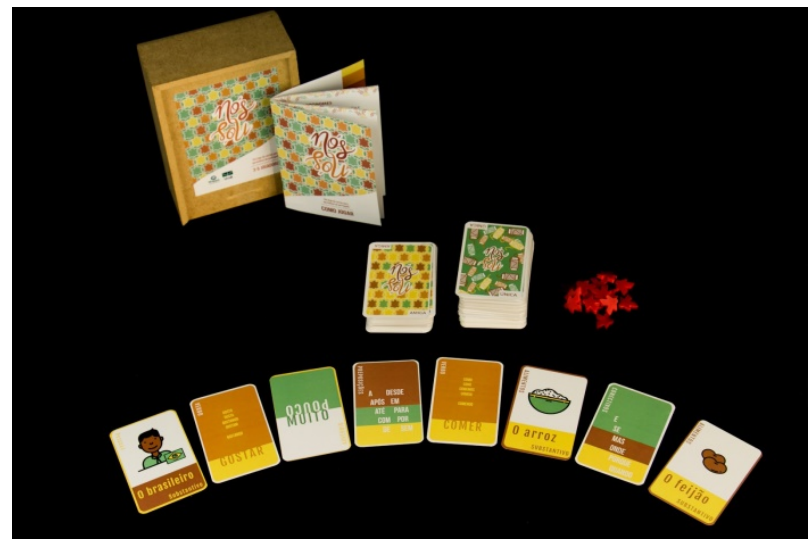

Fonte: Jamile Maeda (2016)

A dinâmica criada pelo o grupo traz à tona a importância da participação de todos os jogadores para o bem comum: formar a oração ou o período de sentido completo. Além disso, faz que a vitória não seja um ponto focal - pois esta se dá com certa aleatoriedade, a depender do sorteio de cartas e de seu descarte -, mesmo que tenha sua importância para a finalização da partida.

Sabe-se que a construção de períodos completos é uma tarefa complexa e exige certo conhecimento prévio da língua; por isso, o jogo foi desenvolvido de modo que pudesse ter sua dificuldade ajustada - neste caso, pode-se retirar ou acrescentar à partida cartas de preposições, conectivos e de verbos transitivos ou realizar nova distribuição de cartas a todos os jogadores, ampliando a possibilidade de escolha. Esta mecânica foi elaborada como estratégia para sua adequação nos três níveis do projeto ProAcolher, com abertura para comportar mais cartas, como novos substantivos, adjetivos, advérbios ou verbos.

A dinâmica desenvolvida para o jogo, da forma como descrita acima, contém detalhes de jogabilidade que consolidam, de maneira funcional e coerente, o objetivo de ensino-aprendizagem almejado, sendo esta relatada no manual que integra o protótipo. Após a satisfação encontrada nesta proposta idealizada e piloto, foi reconhecida e incentivada pelo grupo criador a abertura para a apropriação dos elementos do jogo de forma a gerar novas mecânicas. Essa definição de projeto ocorreu devido à alta heterogeneidade do ambiente de sala de aula do núcleo, à fluidez da didática de português língua de acolhimento, aos interesses específicos do mediador, à quantidade de jogadores e ao tempo disponível para sua aplicação.

\section{Testes com o Jogo Nós}

O protótipo do jogo foi formalmente apresentado à equipe do núcleo, que conheceu sua mecânica e seus componentes por meio da simulação de um turno do jogo realizada pela equipe criadora, conforme a mecânica piloto idealizada pelo grupo. O material recebeu feedbacks positivos e consentimento para sua aplicação em sala. Esse primeiro experimento resultou em sugestões de melhoria, contemplando adequações de cor e da hierarquia de informação das cartas - tema que merece ser tratado em futuras publicações sobre o projeto, a partir de propostas recentes de redesign que aprofundam questões pertinentes ao design gráfico. 
Uma outra aplicação do jogo se deu em campo, a fim de se obter dados sobre sua apropriação fora de um ambiente controlado. O experimento aconteceu durante uma aula do primeiro semestre de 2017 do nível iniciante, mediado pela professora Ingrid Sinimbu Cruz, pesquisadora de ensino-aprendizagem de português língua de acolhimento e principal interlocutora do projeto, e com pouca interferência dos designers envolvidos. Estes se ocuparam de observar as interações, registrá-las em cadernetas e fotografias, além de serem apoios em momentos pontuais (como na distribuição de cartas e no auxílio aos aprendizes com dificuldades em expressar determinada contribuição no jogo).

A professora recebeu uma breve instrução sobre a mecânica do jogo, aproximadamente vinte minutos antes de apresentá-lo aos imigrantes. Como era interlocutora do projeto e como havia participado dos momentos de briefing e apresentação do protótipo, já estava familiarizada com sua estrutura e aberturas para o improviso de novas regras a depender do contexto.

Foi feita uma apresentação breve dos designers presentes na sala e a professora seguiu conduzindo a distribuição de cartas (três Únicas e duas Amigas, conforme instruções iniciais do jogo) e informou que o objetivo era construir frases colaborativamente a partir do conteúdo das cartas recebidas.

O jogo foi conduzido, tratando os presentes como um único grupo. Todos estavam sentados em semicírculo, frente ao quadro - recurso que substituiu a ordenação de cartas sobre a mesa descrita na mecânica piloto (Figura 5). A mediadora lançou perguntas que incitavam a formação de períodos, como: 'alguém quer começar uma frase?', 'alguém tem um sujeito?'. Depois de enunciado um substantivo, ela escrevia a palavra falada no quadro e usava de novas indagações para exercitar o vocabulário para além das frases do jogo - exemplo: 'alguém está de vestido?', quando a palavra anunciada fora 'vestido'. A rodada seguia com contribuições livres de termos que, ordenados na escrita do quadro, revelavam frases cocriadas.

Figura 5 - Professora Ingrid Sinimbu Cruz escrevendo as orações formadas coletivamente em sala no quadro branco

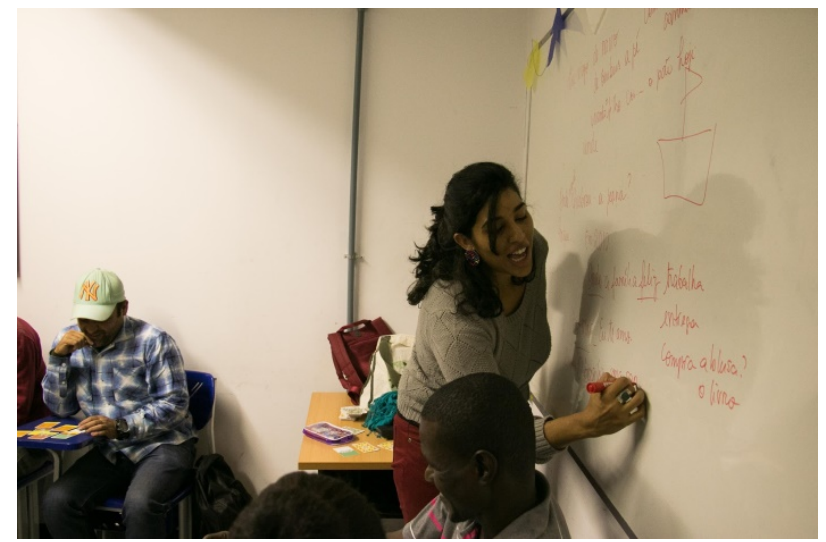

Fonte: Jamile Maeda (2017)

A semântica foi espontaneamente questionada por um dos aprendizes no momento de construção da oração 'A manga vendo', o que invalidou sua construção e possibilitou outras relações de termos a partir de novas citações. A investigação semântica também ocorria a partir de verbos como passar, momento em que a mediadora guiava o aprendizado de interpretações possíveis fazendo uso de gestos e desenhos sobre o quadro. 
Durante o experimento, quando um novo aprendiz chegava à sala, ele ou ela era rapidamente inserido(a) na dinâmica, recebendo cartas e se integrando aos poucos na sequência de sugestões que emergiram. A professora distribuía mais cartas também em momentos em que o vocabulário aparentava ter se exaurido ou levava a repetições pouco criativas na estruturação dos períodos. Decorridos trinta minutos de jogo, foram escritos mais de vinte períodos, e o exercício se encerrou com dezessete participantes em sala, além da mediadora e da equipe de designers.

\section{Resultados Obtidos}

Uma entrevista semiestruturada foi conduzida com a professora Sinimbu Cruz poucos dias após a realização do experimento. Com duração de, aproximadamente, 40 minutos, foram recolhidas suas impressões e sugestões de ajustes para o jogo. Foram listadas sete perguntas norteadoras como ‘de que maneira o jogo somou à didática em sala de aula?' e 'o jogo mostrou-se útil para a turma iniciante do módulo de acolhimento?'.

$\mathrm{Na}$ visão da professora, os aprendizes se mostraram abertos ao jogo e motivados com a nova didática em sala de aula. A falta de rigidez de regras não pareceu incomodar os aprendizes, que levaram alguns minutos para se sentirem à vontade para participar. Uma vez tendo compreendido a dinâmica proposta, orações e alternativas de composição foram formadas. A professora relatou que não foi possível identificar se as jogadas dos alunos foram conscientemente articuladas em relação às gramaticalidades ou não, no entanto essa determinação, na visão dela, não teve muita relevância. O jogo propiciou a aprendizagem de novas palavras, como a diferença entre passear e passar, e de novas estruturas como 'quebrar a perna' e, ainda, o compartilhamento de experiências como 'quebrei minha perna em 2010'. Foi citada a facilidade de se mostrar o desenho das cartas, em vez de recorrer a desenhos ou a traduções para a língua nativa do aprendiz (Figura 6).

Figura 6 - Aprendiz do nível iniciante do ProAcolher, no NEPPE, durante a aula da professora Ingrid S. Cruz, mostrando a carta 'arroz', que tinha em mão para seus colegas de sala

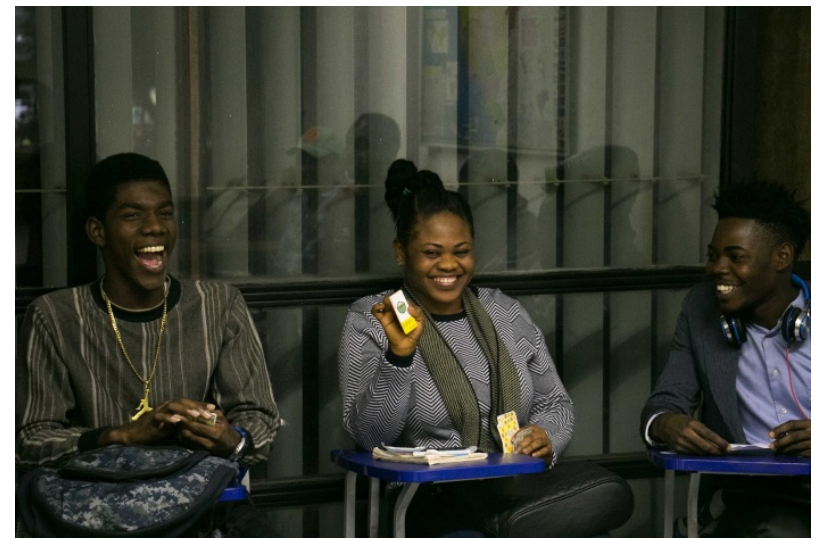

Fonte: Jamile Maeda (2017)

Comentou-se que a aplicação em pequenos grupos, com uma jogabilidade próxima ou igual à sugerida na mecânica piloto, poderia facilitar a participação daqueles que aparentavam timidez para expressar sugestões. Frente a muitos aprendizes, porém, seria necessário um mediador por grupo, exigindo um maior número de pessoas capacitadas em sala.

Sobre as características gráficas, foi apontada a necessidade de alterações em cartas com 
preposições, pronomes e conectivos, pois a apresentação com múltiplas escolhas em uma única carta confundiu alguns aprendizes que, em vez de escolherem apenas uma opção, citavam todas. Ao baralho de cartas Únicas, foi sugerido que se acrescentasse cartas com nomes de cidades e comida brasileiras famosas e com os nomes próprios brasileiros mais comuns, para que se compartilhassem experiências culturais do país que acolheram os aprendizes.

\section{Conclusões}

As principais conclusões deste projeto estão relacionadas ao processo criativo em contato direto com os usuários na etapa de exploração do problema. A abordagem empática no processo de design, que foi propiciada pelas entrevistas com as professoras e com a coordenadora do núcleo e pela participação em aulas e em atividades extras de confraternização, mostrou-se bastante eficaz para um maior entendimento de uma situação política em desordem global (considerando-se o cenário de refúgio contemporâneo ao projeto) e de complexa heterogeneidade a nível local (particularidades do projeto ProAcolher). Aproximou aqueles que propõem as soluções àqueles representantes de um universo até então desconhecido pelo grupo de estudantes de design e que necessitam de cuidados ainda não plenamente providenciados pelos órgãos públicos brasileiros. Tal aproximação é capaz de revelar requisitos informacionais de projeto, oportunidades criativas e transcender o objeto proposto de forma a potencializar laços afetivos por parte de seus usuários finais. Pôde-se concluir também que é possível ao designer ser um agente colaborador de mudanças sociais, em seus esforços para se compreender pessoas e o seu contexto, cocriando novas relações em sociedade por meio de pequenos projetos de alto impacto.

Ressalta-se a necessidade de novas aplicações do jogo, uma vez que ele foi testado somente no nível iniciante, nas condições relatadas. Acredita-se que futuros resultados poderão indicar mais caminhos para melhorias do jogo, sendo prevista a impressão resultante de um redesign após realizados os ajustes gráficos necessários. Reconhecendo a potência de reaplicação do jogo em instituições afins, propõe-se ainda estudos para uma versão de baixo custo, tendo por finalidade sua ampla divulgação acompanhada por tutorial de fabricação.

\section{Referências}

ANÇÃ, M. H. S. F. Língua portuguesa em novos públicos. In: Saber (e) Educar, n.o 13, p. 71-87, 2008.

BARROS, T. Reflexões sobre game design: o planejamento e a experiência de jogo. In: BARROS, T; SARMET, M.; SILVINO, A. (orgs.) Gameplay: ensaios sobre estudo e desenvolvimento de jogos, p. 17-48. Brasília: Ediciones CIESPAL, 2016.

BRASIL. LEI № 9.474, DE 22 DE JULHO DE 1997. Define mecanismos para a implementação do Estatuto dos Refugiados de 1951, e determina outras providências. (http://www.planalto.gov.br/ccivil_03/leis/L9474.htm)

BRITISH COUNCIL. The Design Process: What is the Double Diamond?. In: Design Council, 2015. (http://www.designcouncil.org.uk/news-opinion/design-process-what-double-diamond)

BROTTO, F. O. Jogos cooperativos: o jogo e o esporte como um exercício de convivência. São Paulo: Palas Athena, 2012.

Pedagogia da cooperação: cultivando um mundo onde todos podem VenSer juntos. In: 
Projeto Cooperação, s.d. (http://www.projetocooperacao.com.br/publicacoes/a-pedagogia-dacooperao-construindo-um-mundo-onde-todos-podem-venser)

BROWN, T. Design Thinking: uma metodologia poderosa para decretar o fim das velhas idéia. Rio de Janeiro: Elsevier, 2010.

CAVALCANTI, L. et al., (org.) Dicionário crítico de migrações internacionais. Brasília: Editora Universidade de Brasília, 2017.

GROSSO, M. J. R. Língua de acolhimento, língua de integração. In: Horizontes de Linguística Aplicada, v.9, n. 2, p. 61-77, 2010.

HAGUETTE, T. M. F. Metodologias qualitativas na sociologia. 12.ed. Petrópolis: Vozes, 2010.

KNEMEYER, D. Information Design: The Understanding Discipline. In: Boxes and arrows, 2013. (http://boxesandarrows.com/information-design-the-understanding-discipline)

MAIA, R. F.; Maia, J. F.; Marques, M. T. Jogos cooperativos x jogos competitivos: um desafio entre o ideal e o real. In: Revista Brasileira de Educação Física, Esporte, Lazer e Dança, v.2, n. o 4, p. 125139, 2007.

MIURA, M. A; BARROS, T. A experiência lúdica. In: BARROS, T; SARMET, M.; SILVINO, A. (orgs.) Gameplay: ensaios sobre estudo e desenvolvimento de jogos, p. 155-174. Brasília: Ediciones CIESPAL, 2016.

NEPPE. In: Instituição, s.d. (http://www.neppe.unb.br/br)

OXFORD UNIVERSITY PRESS. Ubuntu. In: Oxford Dicionaries, 2017. (https://en.oxforddictionaries.com/definition/ubuntu)

SHEDROFF, N. Information Interaction Design: a unified field theory of design. In: JACOBSON, R. E. (Ed.) Information design. Cambridge, MA: MIT Press, 1999. p. 267-292.

SOLER, R. Jogos Cooperativos. 3.ed. Rio de Janeiro: Sprint, 2006. 